\title{
THE NOVEL ROLE OF RESVERATROL IN ATTENUATING CISPLATIN INDUCED TESTICULAR TOXICITY IN RATS.
}

1. MBBS, M.Phil (Physiology) Senior Lecturer Physiology ISRA University, Hyderabad.

2. MBBS, MSc (Public Health) Assistant Professor Community Medicine

ISRA University, Hyderabad.

3. MBBS, MSc (Pharmacology) Postgraduate Trainee Biological and Biomedical Sciences

Glasgow Caledonian University, Scotland.

4. MBBS, M.Phil (Physiology) Senior Lecturer Physiology ISRA University, Hyderabad.

5. MBBS, M.Phil (Pharmacology) Senior Lecturer Pharmacology ISRA University, Hyderabad.

6. MBBS, M.Phil (Pharmacology) Lecturer Pharmacology ISRA University, Hyderabad.

Correspondence Address: Dr. Kumayl Abbas Meghii Department of Physiology ISRA University, Hyderabad. dr.kumaylabbas@gmail.com

Article received on:

07/01/2020

Accepted for publication: $16 / 03 / 2020$
Kumayl Abbas Meghji', Tariq Feroz Memon², Ahsan Aslam ${ }^{3}$, Naila Noor ${ }^{4}$, Ali Abbas ${ }^{5}$, Rizwan Ahmed Memon ${ }^{6}$

ABSTRACT... Objectives: To evaluate the anti-oxidative role of Resveratrol in Cisplatin-induced testicular toxicity in Albino Wistar rats. Study Design: Quasi-experimental study. Settings: Department of Physiology and Postgraduate Laboratory of ISRA University Hyderabad. Period: Six months from March to September 2019. Material \& Methods: Twenty-four male albino Wistar rats were distributed equally into; Group-I (Control), Group-II (Cisplatin), Group-III (Cisplatin + Resveratrol). Difference in mean pre and post-experimental body weight was observed while analysis of oxidative markers, semen parameters, and histomorphology was carried out in all three groups. SPSS ver. 22 was used to analyze the data. Results: The mean body weight decreased from $241.7 \pm 8.5 \mathrm{gm}$ to $196.50 \pm 9.34 \mathrm{gm}$ and from $237 \pm 7.4 \mathrm{gm}$ to $210.0 \pm 6.50 \mathrm{gm}$ in groups II and III respectively. Statistically significant reduction in semen parameters (sperm count, motility and viability) was observed in Group-II compared with Group-C $(p<0.05)$. Oxidative markers were also significantly depleted in Group-II in comparison to Group-C $(p<0.05)$. Histologically, testicular structure was found to be intact in Group-I. Marked changes were observed in testicular histology of Group-II while Group-III displayed less testicular damage. Irregular, regressive and atrophic seminiferous tubules were seen in Group-II. Most seminiferous tubules having normal morphology were observed in Group-III while the number of atrophic and degenerative seminiferous tubules also decreased significantly. Conclusion: Resveratrol therapy is a potent protective regime showing promising results in cisplatin-induced testicular toxicity and oxidative stress.

Key words: $\quad$ Antioxidants, Cisplatin, Glutathione Peroxidase, Oxidative Stress, Resveratrol.

Article Citation: Meghji KA, Memon TF, Aslam A, Noor N, Abbas A, Memon RA. The novel role of resveratrol in attenuating cisplatin induced testicular toxicity in rats. Professional Med J 2020; 27(9):2023-2029.

DOI: 10.29309/TPMJ/2020.27.09.4469

\section{INTRODUCTION}

Every year, 5-30\% of couples worldwide experience fertility problems, with higher rates found in yet-developing countries. ${ }^{1,2}$ One of the major causes of failure to conceive as well as a common reproductive disorder is male factor infertility, which accounts for $40-60 \%$ of all fertility problems. ${ }^{3}$ Infection and inflammation of the male reproductive tract, particularly the testes, is the second most prevalent etiology of male infertility. ${ }^{4}$ Moreover, recent studies have also highlighted oxidative stress as an important contributing factor to testicular dysfunction. ${ }^{4,5}$

Cisplatin (cisplatinum or cis-diamminedichloroplatinum) is a chemotherapeutic agent that is also called as "penicillin of cancer" due to its utiliza- tion in the treatment of numerous different types of carcinomas. ${ }^{6,7}$ Clinically, however, the usage of cisplatin is often restricted owing to its many side effects such as renal toxicity, ototoxicity, neurotoxicity, cardiotoxicity, and gonadal toxicity. ${ }^{8-12}$ Various previous experimental studies have high lightened the toxic effects of Cisplatin in testicular tissue. ${ }^{13-15}$

The underlying pathophysiology of testicular cytotoxicity induced by cisplatin has been attributed to disruptions in tissue physiology and biochemistry by producing Reactive Oxygen Species (ROS) and oxidative stress. ${ }^{14,15}$ Cisplatin-induced formation of ROS in testis causes seminiferous tubule damage with germ cell apoptosis, dysfunction of Leydig cells 
and disorder of testicular steroidogenesis and culminating infertility. ${ }^{16}$ On this basis, many antioxidants such as Ginkgo biloba, Ginger Extract, and Beetroot Juice, cinnamon and Fucoidan, etc. have been indicated to protect spermatogenic cells against $\mathrm{CIS} \square$ induced cytotoxicity. ${ }^{12-15}$

Resveratrol (trans-3,4',5-trihydroxystilbene) (RSV) is a polyhydroxyphenol plant toxin (phytoalexin) present in several eatable plants, including grapes, raspberries, etc. ${ }^{16}$ Due to its potent antioxidant potential, in recent years, there has been a consensus regarding the positive effects of RSV, leading to the usage of this drug for the prevention and treatment of various disease conditions. ${ }^{17}$ RSV reduces lipid peroxidation by its free radical scavenging ability, improves the activities of a variety of antioxidant enzymes and prevents DNA damage. By doing so, RSV alleviates oxidative stress by increasing endogenous antioxidant levels such as superoxide dismutase (SOD), glutathione peroxidase (GPX) and catalase (CAT). ${ }^{18}$

In this study, we aimed to investigate cisplatin's gonadotoxic side effects in the rat testis and the possible beneficial antioxidant and anti-apoptotic effects of RSV by histochemical, ultrastructural and biochemical methods.

The findings of this study will be significant in studying the effects of cisplatin causing renal dysfunction in human populations.

\section{MATERIAL \& METHODS}

\section{Study Design}

Quasi-Experimental Study.

\section{Settings}

Department of Physiology and Postgraduate Laboratory of ISRA University Hyderabad.

\section{Duration}

Six months from March 2019 to September 2019.

\section{Methods}

The animal protocol was carried out at Animal House, Department of Husbandry and Veterinary
Sciences, Sindh Agricultural University Tandojam after taking approval from Isra University Ethical Review Board. By applying non-random sampling technique, Twenty-four albino Wistar male rats of $150-250 \mathrm{gm}$ were selected. The animals were kept in the stainless steel cages (with sawdust bedding renewed every day). Lab chow and tap water ad libitum were given to all rats. Proper ventilation and hygienic environment was ensured. While the room temperature was maintained at $26 \circ \mathrm{C}$ with light/dark cycle of 12 hours. After an acclimatization period of 10 days, all rats were uniformly distributed in three groups.

Group I (Control) ( $\mathrm{n}=8$ rats) received normal chow diet along with clean water ad libitum.

Group II (Cisplatin) ( $n=8$ rats) received single dose of cisplatin $(7 \mathrm{mg} / \mathrm{kg})$ intraperitoneally with normal diet.

Group III (Cisplatin + Resveratrol) ( $n=8$ rats) received single dose of cisplatin $(7 \mathrm{mg} / \mathrm{kg})$ intraperitoneally followed by Resveratrol $(10 \mathrm{mg} /$ $\mathrm{kg}$ ) orally for 21 days.

The level of the orally administered dosage of Resveratrol (10 mg/kg bwt) and intraperitoneal dose of Cisplatin ( $7 \mathrm{mg} / \mathrm{kg}$ bwt intraperitoneally) was based on previous works. . $^{19,20}$ After completion of the experiment, the weight of all animals was measured by electronic measuring balance. All the rats were given anesthesia (chloroform soaked cotton) and sacrificed by cervical dislocation. Blood samples for biochemical analysis were collected by cardiac puncture. The abdomens of experimental animals were dissected through a midline incision. After properly identifying, testes were removed and their weight was recorded. For estimation of morphology and motility, suspension of the epididymal content was formed by removing cauda epididymis of one testis that was then macerated by scissors in a Petri dish having normal saline $(3 \mathrm{ml})$. Similarly, for sperm count, suspension of the epididymal content was formed by removing cauda epididymis of the other testis that was then macerated by scissors in a Petri dish containing $0.9 \mathrm{ml}$ of $10 \%$ formalin. Once the testicular tissue had been fixed in Bouin's fluid, longitudinal cut sections were obtained. After appropriately arranging the 
tissues in tagged cassettes, they were passed through water. To rid the tissues of any excess fixative, they were placed in a solution of lithium carbonate in $70 \%$ alcohol. Tissue blocks were obtained after passing samples through the alcohol in ascending grades from $70 \%-100 \%$ and embedded within paraffin wax. Cut sections of $5 \mu \mathrm{m}$ thick-were obtained using a rotary microtome and stained by Hematoxylin and Eosin (H\&E).

Serum SOD, GPX and CAT levels were analyzed using bioassay technology ELISA kits on DiaSource ELISA plate reader (RT 0931117 DIA) at Diagnostic Laboratory, Isra University, Hyderabad.

The descriptive and inferential analysis of data in this study was carried out using the Statistical Package for the Social Science version 21.0 (SPSS Inc.; Chicago, IL). Descriptive data was expressed as Mean $\pm S D$ while statistical significance level was evaluated using one-way ANOVA. Post hoc Tukey's test was used to compare the findings between the groups. Significance level was set at $\mathrm{p} \leq 0.05$.

\section{RESULTS}

Pre-experimental body weight (Mean \pm SD) of group I, II and III was 239.3 $\pm 5.7 \mathrm{gm}, 241.7 \pm 8.5$ gm, and $237 \pm 7.4 \mathrm{gm}$ respectively. Weight of all animals was measured again after completion of experiment. Significant difference in mean postexperimental body weight was observed in all three groups i.e. in Group I there was a rise in body weight $(246.8 \pm 6.35 \mathrm{gm})$ while in Group II significant decline in mean body weight (196.70 $\pm 9.30 \mathrm{gm}$ ) and in group III a similar decline was also observed $(210.0 \pm 6.50 \mathrm{gm})$, however, the weight loss was not as much as seen in Group II. Statistically significant difference of $p<0.05$ was observed between the experimental groups (Table-I). While difference in the mean testicular weight was also observed statistically significant in all three groups $(p<0.05)$. A significant decline in mean testicular weight was observed in Group II compared with Group I. However, no significant difference was observed in testicular weight between Group III and I (Table-I).
Cisplatin treatment significantly decreased sperm count, motility, and viability in Group II in comparison to Group I $(p<0.05)$. While, no significant difference in semen parameters was observed between groups III and I (Table-I).

A significant difference in Antioxidant levels (GPX, SOD, and CAT) was observed in all three groups $(p<0.05)$. Post hoc analysis revealed a significant decline in levels of GPX, SOD, and CAT in Group II in comparison with Group I controls. While significantly higher levels of antioxidants in Group III were observed as compared with Group II $(p<0.05)$. Furthermore, no statistical difference in antioxidant levels amongst Group III and Group I. (Table-II)

Experimental animals in-group I exhibited normal testicular architecture with regular seminiferous tubules. Rats treated with Cisplatin (Group II) showed marked disruption of normal testicular architecture with irregular small seminiferous tubules and absence of spermatogenesis. Degenerative, regressive and atrophic tubules were also observed. RSV treated rats (Group III) showed near-normal testicular architecture with most seminiferous tubules having normal morphology similar to Group I. Moreover, the number of atrophic and degenerative seminiferous tubules also decreased significantly.

Figure-1. Photomicrograph (H\&E 400x) of testicular cross-sections showing I - Normal histological architecture with intact seminiferous tubules. II - Irregularities within the seminiferous tubules such as Sertoli cells only without any spermatogenic cells in the group. III - Regular structured seminiferous tubules and few spermatids along with normal Sertoli cells in the group.3

\section{DISCUSSION}

Conditions that mostly endanger the well-being of the reproductive system, particularly testicular function, are associated with oxidative stress induced by free radicals. Lethal attacks of these free radicals may cause occlusion of arteries and critical injury to the reproductive system cells leading to imperfections in spermatogenesis. ${ }^{21}$ 


\begin{tabular}{|c|c|c|c|}
\hline Parameters & Group I & Group II & Group III \\
\hline Testis weight (g) & $1.55 \pm 0.37$ & $1.02 \pm 0.18^{*}$ & $1.39 \pm 0.64^{\times}$ \\
\hline Body weight (g) & $246.8 \pm 6.35$ & $196.70 \pm 9.30 *$ & $210.0 \pm 6.50 *$ \\
\hline Motility (\%) & $71.84 \pm 5.25$ & $27.79 \pm 3.66^{\star}$ & $66.74 \pm 4.56^{\times}$ \\
\hline Viability (\%) & $80.33 \pm 2.86$ & $51.86 \pm 3.36^{\star}$ & $68.11 \pm 2.26^{x}$ \\
\hline
\end{tabular}

\begin{tabular}{|c|c|c|c|}
\hline Parameters & Group I & Group II & Group III \\
\hline Superoxide dismutase (u/mg protein) & $13.18 \pm 0.45$ & $5.89 \pm 0.16^{*}$ & $11.40 \pm 0.84^{\times}$ \\
\hline \multicolumn{4}{|c|}{$\begin{array}{l}\text { Table-II. Multiple comparison of glutathione peroxidase, superoxide dismutase and catal } \\
\text { Post-Hoc Tukey Test } \\
\text { Level of significance } \mathrm{p}<0.05 \\
\text { *: Significant difference as compared with control group } \\
\times \text { : Significant difference as compared with group II (Cisplatin) }\end{array}$} \\
\hline
\end{tabular}
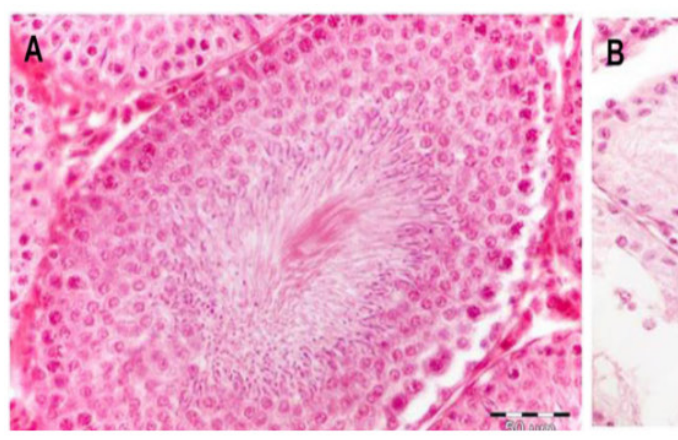

Owing to increased cell division rate, increased cell competition for oxygen and low oxygen pressure due to weakened vessels, testicular tissue is highly predisposed to oxidative stress. ${ }^{21}$

The current study attempted to highlight the deleterious effects of Cisplatin on reproductive health. The results showed that cisplatin not only induces histological alterations in normal testicular architecture but also causes oxidative stress with depletion of anti-oxidant levels. RSV administration ameliorated all the biochemical and histopathological disruptions by protecting against testicular cytotoxicity resulting from the induction of Cisplatin.

As mentioned earlier, Cisplatin is one of the most potent anti-cancer agents available used in the treatment of a wide variety of cancers including cancers of the urogenital tract. The use of Cisplatin, however, is considered as a doubleedged sword as its side effects often outweigh its therapeutic benefits. The toxic effects of Cisplatin are attributed to its capability to generate ROS, which leads to depletion of anti-oxidant levels and ultimately oxidative stress..$^{17,22}$

In the present study, Cisplatin administration was followed by a reduction in body weight of experimental animals as well as a reduction in semen parameters. It also caused marked disturbances in anti-oxidant levels and substantial alterations in normal testicular histology. These findings are consistent with the findings of Hamza 
et al. who reported cisplatin administration not only had a deleterious effect on testicular histology but also on semen parameters. ${ }^{23}$ In this study, we observed that cisplatin treatment caused a marked decline in endogenous anti-oxidant levels (GPX, SOD, and CAT). These findings are similar to the findings of previous studies by Al-Bader et al. and Madhu et al. ${ }^{24,25}$

As a polyphenolic phytoalexin, Resveratrol has been reported to be beneficial for the prevention of testicular toxicity caused by numerous different toxic agents such as Doxorubicin ${ }^{26}$, Phthalate ${ }^{27}$, Methotrexate ${ }^{28}$, High Fructose ${ }^{29}$, etc. Consistent with these observations, the results of this current study show the positive effects of Resveratrol in the prevention of Cisplatin-induced testicular toxicity and dysfunction as concluded from increased semen parameters as well as antioxidant levels.

Nagehan et al. and Reddy et al. reported similar findings where RSV treatment ameliorated Cisplatin-induced testicular toxicity by lowering oxidative stress. RSV treatment prevented Cisplatin-induced weight loss as well as improved semen parameters i.e. sperm count, motility and viability. RSV treatment also caused an increase in endogenous antioxidant levels and reduced overall oxidative stress. Moreover, RSV therapy also prevented cisplatin-induced histological alterations in testicular architecture. These findings are consistent with the findings of the current study. ${ }^{16,30}$

However, there were certain limitations to the current study. Due to the limited availability of time and monetary resources, laboratory tests pertaining to inflammatory markers and hormonal assays could not be accomplished. Therefore, further supplementary research is recommended to assess various effects of RSV on inflammatory and hormonal parameters and to explore the effects of RSV in combination with other antioxidants such as Ascorbic acid and Ginkgo biloba extract, etc.

\section{CONCLUSION}

This study showed a protective effect of Resveratrol against cisplatin induced testicular toxicity. Reduction of oxidative stress may be considered as one of the main pathways of action. Copyright@ 16 Mar, 2020.

\section{REFERENCES}

1. Ji G, Gu A, Wang Y, Huang C, Hu F, Zhou Y, et al. Genetic variants in antioxidant genes are associated with sperm DNA damage and risk of male infertility in a Chinese population. Free Radical Biology and Medicine. 2012; 52(4):775-80.

2. Hu M, Zhang Y, Ma H, Ng EH, Wu X-K, editors. Eastern medicine approaches to male infertility. Seminars in reproductive medicine; 2013: Thieme Medical Publishers.

3. Esteves SC, Miyaoka R, Agarwal A. An update on the clinical assessment of the infertile male. Clinics. 2011; 66(4):691-700.

4. Wang J, Wang W, Li S, Han Y, Zhang P, Meng G, et al. Hydrogen sulfide as a potential target in preventing spermatogenic failure and testicular dysfunction. Antioxidants \& redox signaling. 2018; 28(16):1447-62.

5. Chen S-j, Allam J-P, Duan Y-g, Haidl G. Influence of reactive oxygen species on human sperm functions and fertilizing capacity including therapeutical approaches. Archives of gynecology and obstetrics. 2013; 288(1):191-9.

6. Barabas K, Milner R, Lurie D, Adin C. Cisplatin: A review of toxicities and therapeutic applications. Veterinary and comparative oncology. 2008; 6(1):1-18.

7. Cao X, Xiong S, Zhou Y, Wu Z, Ding L, Zhu Y, et al. Renal protective effect of hydrogen sulfide in cisplatininduced nephrotoxicity. Antioxidants \& redox signaling. 2018; $29(5): 455-70$.

8. Gómez-Sierra T, Eugenio-Pérez D, SánchezChinchillas A, Pedraza-Chaverri J. Role of foodderived antioxidants against cisplatin inducednephrotoxicity. Food and chemical toxicology. 2018; 120:230-42.

9. Sarafraz Z, Ahmadi A, Daneshi A. Transtympanic injections of $\mathrm{N}$-acetylcysteine and dexamethasone for prevention of cisplatin-induced ototoxicity: Double blind randomized clinical trial. The international tinnitus journal. 2018; 22(1):40-5. 
10. Turan M, Cayir A, Cetin N, Suleyman H, Turan IS, $\operatorname{Tan} H$. An investigation of the effect of thiamine pyrophosphate on cisplatin-induced oxidative stress and DNA damage in rat brain tissue compared with thiamine: Thiamine and thiamine pyrophosphate effects on cisplatin neurotoxicity. Human \& experimental toxicology. 2014; 33(1):14-21.

11. Coskun R, Turan MI, Turan IS, Gulapoglu M. The protective effect of thiamine pyrophosphate, but not thiamine, against cardiotoxicity induced with cisplatin in rats. Drug and chemical toxicology. 2014; $37(3): 290-4$.

12. Amin A, Abraham C, Hamza AA, Abdalla ZA, Al-Shamsi SB, Harethi SS, et al. A standardized extract of Ginkgo biloba neutralizes cisplatin-mediated reproductive toxicity in rats. BioMed Research International. 2012; 2012.

13. Elshiekh AA, Elkolaly HR, Tawfeek NM, Mohamed AA, Mohamed AA. Possible protective effect of ginger extract and beetroot juice against cisplatin induced testicular and cytogenetic toxicity in adult male albino rats. Egyptian Journal of Hospital Medicine. 2019; 76(5).

14. Okdah YA, Kandil EH. Potential therapeutic effect of cinnamon against cisplatin-induced testicular toxicity and oxidative stress in rats. Transylvanian Review. 2018; 1(12).

15. Tutuncu M, Kiray M, Yonguc N, Bagriyanik HA, editors. The protective effects of fucoidan on cisplatin induced testicular cytotoxicity in rats. Multidisciplinary Digital Publishing Institute Proceedings; 2018.

16. Özyilmaz Yay N, Şener G, Ercan F. Resveratrol treatment reduces apoptosis and morphological alterations in cisplatin induced testis damage. Marmara Pharmaceutical Journal. 2019; 23(4).

17. Meghji KA, Talpur RA, Uqaili AA, Nizammani YM, Kazi $\mathrm{N}$, Nizammani GS. Resveratrol attenuates oxidative stress in chemotherapy induced acute kidney injury: An experimental rat model. Khyber Medical University Journal. 2019; 11(2).

18. Tatlidede E, Şehirli Ö, Velioğlu-Öğünç A, Çetinel Ş, Yeğen BÇ, Yarat $A$, et al. Resveratrol treatment protects against doxorubicin-induced cardiotoxicity by alleviating oxidative damage. Free radical research. 2009; 43(3):195-205.

19. Şener G, Topaloğlu N, Şehirli AÖ, Ercan F, Gedik N. Resveratrol alleviates bleomycin-induced lung injury in rats. Pulmonary pharmacology \& therapeutics. 2007; 20(6):642-9.
20. Köroğlu KM, Çevik Ö, Şener G, Ercan F. Apocynin alleviates cisplatin $\square$ induced testicular cytotoxicity by regulating oxidative stress and apoptosis in rats. Andrologia. 2019; 51(4):e13227.

21. Asadi N, Bahmani M, Kheradmand A, Rafieian-Kopaei $M$. The impact of oxidative stress on testicular function and the role of antioxidants in improving it: a review. Journal of clinical and diagnostic research: JCDR. 2017; 11(5):IE01.

22. Boroja T, Katanić J, Rosić G, Selaković D, Joksimović J, Mišić D, et al. Summer savory (Satureja hortensis L.) extract: Phytochemical profile and modulation of cisplatin-induced liver, renal and testicular toxicity. Food and chemical toxicology. 2018; 118:252-63.

23. Hamza A, Elwy H, Badawi A. Fenugreek seed extract attenuates cisplatin $\square$ induced testicular damage in $\mathbf{W}$ istar rats. Andrologia. 2016; 48(2):211-21.

24. Al-Bader M, Kilarkaje N. Effects of bleomycin, etoposide and cisplatin treatment on Leydig cell structure and transcription of steroidogenic enzymes in rat testis. European journal of pharmacology. 2015; 747:150-9.

25. Madhu P, Reddy KP, Reddy PS. Role of melatonin in mitigating chemotherapy-induced testicular dysfunction in Wistar rats. Drug and chemical toxicology. 2016; 39(2):137-46.

26. Türedi S, Yuluğ E, Alver A, Kutlu Ö, Kahraman C. Effects of resveratrol on doxorubicin induced testicular damage in rats. Experimental and Toxicologic Pathology. 2015; 67(3):229-35.

27. El-Fattah AAA, Fahim AT, Sadik NAH, Ali BM. Resveratrol and curcumin ameliorate di-(2-ethylhexyl) phthalate induced testicular injury in rats. General and comparative endocrinology. 2016; 225:45-54.

28. Yuluğ E, Türedi S, Alver A, Türedi S, Kahraman C. Effects of resveratrol on methotrexate-induced testicular damage in rats. The scientific world journal. 2013; 2013.

29. Meydanli EG, Gumusel A, Ozkan S, Tanriverdi G, Balci MC, Develi Is $S$, et al. Effects of resveratrol on highfructose-induced testis injury in rats. Ultrastructural pathology. 2018; 42(1):65-73.

30. Reddy KP, Madhu P, Reddy PS. Protective effects of resveratrol against cisplatin-induced testicular and epididymal toxicity in rats. Food and chemical toxicology. 2016; 91:65-72. 


\section{AUTHORSHIP AND CONTRIBUTION DECLARATION}

\begin{tabular}{|c|c|c|c|}
\hline Sr. \# & Author(s) Full Name & Contribution to the paper & Author(s) Signature \\
\hline 1 & Kumayl Abbas Meghji & $\begin{array}{l}\text { Acquisition, analysis and } \\
\text { interpretation of data, Drafting } \\
\text { of manuscript, final approval of } \\
\text { the version to be published. }\end{array}$ & \\
\hline 2 & Tariq Feroz Memon & $\begin{array}{l}\text { Data analysis and interpretation, } \\
\text { study design, resutls write-up. }\end{array}$ & tram \\
\hline 3 & Ahsan Aslam & $\begin{array}{l}\text { Drafting of Manuscript and } \\
\text { proof reading. }\end{array}$ & \\
\hline 4 & Naila Noor & $\begin{array}{l}\text { Assistance in experimental work } \\
\text { and histologial interpretations. }\end{array}$ & \\
\hline 5 & Ali Abbas & $\begin{array}{l}\text { Proof reading and review of } \\
\text { references. }\end{array}$ & \\
\hline 6 & Rizwan Ahmed Memon & Proof reading and review. & \\
\hline
\end{tabular}

